\title{
Nurses' attitudes towards the reporting of violence in the emergency department
}

\author{
Kathryn M. Hogarth, MN, GradDip Emerg, RN ${ }^{a, b}$ \\ Jill Beattie, PhD, MN (Adv Pract), BN (Ed) DipT (Nse Ed), RN, RM ${ }^{a}$ \\ Julia Morphet, PhD, MN (Ed), Grad Cert Hlth, Prof Ed, GradDip Emerg, \\ RN $^{\mathrm{a}, *}$
}

\footnotetext{
a School of Nursing and Midwifery, Monash University, Frankston, Victoria 3199, Australia

b Emergency Department, Monash Health, Dandenong Hospital, David Street, Dandenong, Victoria 3175, Australia

Received 22 December 2014; received in revised form 21 March 2015; accepted 26 March 2015
}

\section{KEYWORDS \\ Emergency \\ department; \\ Risk management; \\ Workplace violence; \\ Qualitative research; \\ Nursing; \\ Reporting violence}

\begin{abstract}
Summary
Background: The incidence of workplace violence against nurses in emergency departments is underreported. Thus, the true nature and frequency of violent incidents remains unknown. It is therefore difficult to address the problem.

Aim: To identify the attitudes, barriers and enablers of emergency nurses to the reporting of workplace violence.

Method: Using a phenomenological approach, two focus groups were conducted at a tertiary emergency department. The data were audio-recorded, transcribed verbatim and analysed using thematic analysis.

Results: Violent incidents in this emergency department were underreported. Nurses accepted violence as part of their normal working day, and therefore were less likely to report it. Violent incidents were not defined as 'violence' if no physical injury was sustained, therefore it was not reported. Nurses were also motivated to report formally in order to protect themselves from any possible future complaints made by perpetrators. The current formal reporting system was a major barrier to reporting because it was difficult and time consuming to use. Nurses reported violence using methods other than the designated reporting system.

Conclusion: While emergency nurses do report violence, they do not use the formal reporting system. When they did use the formal reporting system they were motivated to do so in order to protect themselves. As a consequence of underreporting, the nature and extent of workplace violence remains unknown.

(c) 2015 College of Emergency Nursing Australasia Ltd. Published by Elsevier Ltd. All rights reserved.
\end{abstract}

* Corresponding author. Tel.: +61039904 4032.

E-mail address: Julia.morphet@monash.edu (J. Morphet). 


\section{What is known}

- We know violence occurs frequently in the emergency department and we know that emergency nurses' do not report violence. It is necessary to know the nature and extent of this violence so that the occurrence of violence can be managed appropriately.

\section{What this paper adds?}

- Emergency nurses do report violence, however, they use other informal methods rather than using the formal mandated reporting system RiskMan.

- Emergency nurses do not recognise violence to have occurred if no-one was hurt.

- Emergency nurses accept violence as part of their job and they accept 'unintentional' violence from 'sick' patients, whereas they have less tolerance for violence perpetrated by people 'behaving badly'.

\section{Introduction}

Many national and international studies conducted in the past decade have highlighted the alarming incidence of violence perpetrated against nurses, in particular in the emergency department (ED).$^{1-8}$ Violence against nurses has far reaching consequences, not only in terms of nurses' own health and wellbeing, but on the nature of health care delivery and the ability of nurses to provide quality patient centred care. ${ }^{6-10}$ Workplace violence (WPV) is a serious concern for nurses, healthcare organisations, patients and society as a whole, because it has wide spread negative effects. In 1999, Australian nurses rated the second highest among employee groups for workers compensation claims as a result of violence in the workplace. ${ }^{11}$ Since then, violence in nursing, and in particular in emergency departments has been a focus of increasing attention and governmental reports, which indicate a continuing upward trend in violence. ${ }^{7,8,12-14}$

Although there are some measures in place to protect nurses and other ED staff such as education, training in de-escalation techniques, formal incident reporting procedures, and security response teams, assaults against emergency nurses continue to increase and are thus a very real occupational health and safety issue. ${ }^{7,8}$ The literature reveals a major barrier to addressing the problem of violence in EDs is the lack of reporting of violent incidents by nurses. $2,7,8,14-16$ Underreporting is problematic, because it means the true extent of violent incidents occurring in EDs is unknown. ${ }^{16}$ Without adequate data about the number and nature of violent incidents, it remains difficult to develop evidence based strategies to deal with WPV.

Incidents in hospitals, including violent incidents, are reported using state based systems, and each state and territory in Australia has its own reporting system. The state-wide system in Victoria is called the Victorian Health Incident Management System (VHIMS). This software is used in hospitals to report incidents including violence. In 2011
VHIMS, incorporating RiskMan, was introduced to all Victorian hospitals. ${ }^{8}$ Early reports following the implementation of RiskMan indicated that the programme itself may be a barrier to reporting. Staff reported that RiskMan was burdensome and time-consuming and they were reluctant to use it. ${ }^{8}$ Further research is required to identify why nurses are not reporting WPV using their hospital's formal reporting system (e.g. RiskMan in Victoria, Australia). Therefore this study explored the attitudes and factors related to reporting of violence by nurses in the ED.

\section{Aim}

The aim of this study was to identify the attitudes, barriers and enablers of emergency nurses to reporting workplace violence.

\section{Method}

A phenomenological approach ${ }^{17}$ was used to explore the attitudes, barriers and enablers of emergency nurses to reporting workplace violence. The researcher used a phenomenological approach in this study because phenomenology asks "what is the lived experience" of participants in relation to the phenomenon under study. ${ }^{18}$ Thus, in this context, the researcher sought to describe and reveal the meaning of emergency nurses' lived experience in relation to underreporting of WPV.

\section{Setting}

The study was conducted in a large metropolitan ED in Melbourne, Australia, with over 62,000 adult and paediatric patient presentations annually. The hospital is a 640 bed major tertiary referral centre. The emergency department has 42 cubicles and 113 full time equivalent nursing staff.

\section{Sample}

Purposive sampling included those emergency nurses who had knowledge and experience of violence in the ED. Thus, participants were invited on the basis of their knowledge of the phenomenon being studied. All emergency nurses currently working in the ED were eligible to participate.

\section{Ethics}

Ethics approval to conduct the study was obtained from the Monash University Human Research Ethics Committee (CF12/1357) and the relevant hospital ethics committee (Approval number 12199L).

\section{Recruitment of participants}

Fliers promoting the study were placed on notice boards in the ED, and a member of the research team spoke to staff about the study at one of the regular staff meetings. A brief explanation of the study was provided and the Participant Information and Consent Form was given to participants to 
read. Participants were then given the opportunity to ask questions. The focus groups were held during double staffing time to increase convenience for those staff who wanted to participate.

\section{Data collection}

Semi-structured interview questions were used to guide the focus group discussions (Table 1). The interview questions were tested in a pilot focus group with nine participants, and results from that focus group indicated that the questions were appropriate, and responses were relevant to the research question. Two focus groups were then conducted two weeks apart in September 2013. Focus Group One lasted 32 min and Focus Group Two lasted 36 min. Each focus group was digitally recorded and transcribed verbatim.

\section{Data analysis}

Focus group transcripts were analysed using thematic analysis. ${ }^{19}$ Initially the transcripts were read and re-read so that the researcher could become familiar with the contents, get a feel for what was being said, and gain initial understanding of participants' experiences. During the re-reading of the text, preliminary codes were identified. Codes were initially centred on the focus group questions as they related to the research questions and the research aims. ${ }^{20}$ For example, reported violence or not reported violence, types of violence, how violence was reported and under what circumstances, expected outcomes of reporting, enablers to reporting, barriers to reporting, and attitudes to reporting. Each text was coded based on these questions, then within each transcript, codes of similar meaning were linked together creating categories, to identify major themes within the text. ${ }^{17}$ From these themes the attitudes of emergency nurses towards violence emerged. ${ }^{19}$ In the results section, data is linked to participants using a code to reflect the focus group (FG) number and the person speaking. For example the fourth participant in FG2 is labelled FG2 P4.

\section{Table 1 Focus group questions.}

\begin{tabular}{ll}
\hline 1 & Have you reported violence in the workplace? \\
2 & Why/when/under what circumstances? \\
3 & When you have reported an incident in the past, \\
& what did you think it would achieve? \\
5 & How did you feel about making a formal report? \\
What are the enablers and barriers to reporting \\
workplace violence? \\
Possible prompts: what things help or assist you \\
to report? What things stop you from reporting? \\
How do you find the reporting process? \\
When you have reported an incident in the past, \\
what response was there?
\end{tabular}

Table 2 Participant demographics.

\begin{tabular}{lll}
\hline Participants & $\begin{array}{l}\text { Focus group } \\
1(n=8)\end{array}$ & $\begin{array}{l}\text { Focus group } \\
2(n=7)\end{array}$ \\
\hline Male & 2 & 1 \\
Female & 6 & 6 \\
Currently in triage & 4 & 0 \\
\hline
\end{tabular}

\section{Results}

Fifteen emergency nurses (male $=3$; female $=12$ ) participated in the two focus groups. Participants had 1-6 years of emergency nursing experience; four participants worked at triage (Table 2).

The results of this study fall into four broad headings: reporting of violence; attitudes to reporting of violence; barriers to formal reporting of violence; and enablers to formal reporting of violence. Examples of these are presented in Table 3 with the evidence from focus group transcripts, and are reported in more detail below.

\section{Reporting of violence}

In this study, participants understood that RiskMan was the formal reporting system for violent incidents. Initially, participants indicated that they had never reported WPV. However, an important finding from this study is that emergency nurses did in fact report WPV, but not using the formal reporting system (RiskMan). They used a number of informal methods to report violence, and did so frequently. For example, violent incidents were documented in the medical record and were reported to nursing colleagues and other staff at the time of the incident.

Participants also reported violence and aggression by entering an electronic alert in the patient record. This acted as a warning to staff of any previous violent behaviour, should the patient present to the ED in future. Nurses also used the existing alarm systems to call for assistance, for example duress alarms.

The only time emergency nurses formally reported violence using the RiskMan system was when the violent incident resulted in a physical injury, or when it was considered important to document, in case of a later complaint by the patient or family.

\section{Attitudes to reporting violence and aggression}

Nurse's attitudes to reporting influenced their decision to report, as described in the following section.

\section{Participants' perception of violence}

The nurses in this study perceived violence to be where a physical injury was sustained from a violent incident. For example, violence was not reported if "no-one was hurt" or the violence was "not hard" enough to cause a physical injury. Violence was formally reported if there was significant physical injury (Table 3 ). 
Table 3 Examples of nurses' attitudes towards reporting violence.

\begin{tabular}{|c|c|}
\hline Factors & Evidence from participant transcripts \\
\hline $\begin{array}{l}\text { Participants' } \\
\text { perception of } \\
\text { violence }\end{array}$ & $\begin{array}{l}\text { Attitudes to reporting } \\
\text { When someone's going off all the time and you know it's not warranted or they have come } \\
\text { in just drunk or behaving badly, I think that's when you get more annoyed. But when } \\
\text { someone's really sick or trying to climb out of bed or like kind of punching you around, you } \\
\text { don't get as annoyed or frustrated or angry, because they are sick. But I find that people get } \\
\text { quite verbally aggressive all the time when it's not warranted, like family are 'arcing up' That } \\
\text { frustrates me more than if they are just actually very sick or quite unwell. (FG 1P1) } \\
\ldots \text { because no one was hurt. It was just verbal abuse. (FG } 2 \text { P6) } \\
\text { Stuff like verbal aggression. You get used to it. You experience it a lot and you don't think } \\
\text { to report it. (FG2 P6) } \\
\text { It would have to be pretty significant verbal abuse for me to report (FG1 P4) } \\
\text { It happens so much you'd only write it down if it was almost a special case (FG1 P1) }\end{array}$ \\
\hline $\begin{array}{l}\text { Violence is part of } \\
\text { the job }\end{array}$ & $\begin{array}{l}\text { Just part of the job (FG2 P7). } \\
\text { It's sort of part of your every day (FG1 P7). } \\
\text { I think that's been the culture of nursing, especially emergency nursing, that it's just part } \\
\text { of the job. I think that's generally what I've experienced and it's actually accepted that we } \\
\text { take it, basically. You have people in crisis, so they are not being themselves because they're } \\
\text { under pressure, so you have to take that psychological or emotional violence towards you as } \\
\text { part of your job (FG2 P7). }\end{array}$ \\
\hline $\begin{array}{l}\text { RiskMan difficult } \\
\text { and time } \\
\text { consuming }\end{array}$ & $\begin{array}{l}\text { Barriers to formal reporting of violence } \\
\text { Using RiskMan is enough to put you off wanting to report (FG2 P7). } \\
\text { Security had been called to ED over a one month period three hundred times and only } \\
\text { received ten RiskMan reports from ED over the same period (FG1 P4). } \\
\text { I think it is important to report it [violence] but the process that's in place for us to report } \\
\text { things, at the moment, is so time consuming that you don't take the time to do it, because } \\
\text { you would spend half your shift doing it (FG1 P1) }\end{array}$ \\
\hline $\begin{array}{l}\text { Lack of clear } \\
\text { policies and } \\
\text { procedures }\end{array}$ & $\begin{array}{l}\text { They [the perpetrators] get put through faster into a cubicle (FG2 P4). } \\
\text { They do. It calms the rest of the waiting room down. Get them in, get them seen and get } \\
\text { them back out (FG2 P5). } \\
\text { The squeaky wheel gets the oil. That's the policy (FG2 P7). }\end{array}$ \\
\hline $\begin{array}{l}\text { Not encouraged to } \\
\text { report }\end{array}$ & $\begin{array}{l}\text { No, no-one ever encouraged me to [report violence]. I mean security comes, people get } \\
\text { shackled when things like that happen. No-one's ever really encouraged adequate } \\
\text { documentation after the event. It's kind of de-escalated and then you hope for the best (FG1 } \\
\text { P7). }\end{array}$ \\
\hline $\begin{array}{l}\text { No preventative } \\
\text { measures post } \\
\text { violent incident }\end{array}$ & $\begin{array}{l}\text { Nothing gets done about that incident and we will deal with the next one when it comes } \\
\text { along (FG1 P1). } \\
\text { The problem is solved at the time but I don't think anything is done after that. I think once } \\
\text { the shift is over that's it. Nothing happens after that (FG1 P4). }\end{array}$ \\
\hline $\begin{array}{l}\text { Reporting for } \\
\text { protec- } \\
\text { tion/prevention }\end{array}$ & $\begin{array}{l}\text { Enablers to reporting of violence } \\
\text { The only reason I would fill out a RiskMan is if I was put into harm's way or if I knew that } \\
\text { something was going to escalate from it. That they [the patient or family member] were going } \\
\text { to report it (FG2 P2). }\end{array}$ \\
\hline $\begin{array}{l}\text { User-friendly } \\
\text { system } \\
\text { Feedback on } \\
\quad \text { formal reports }\end{array}$ & $\begin{array}{l}\text { If it [reporting] were simplified, definitely I would report (FG2 P6). } \\
\text { Definitely! Absolutely! [Would fill in a formal report if easy] (FG2 P6). } \\
\text { That's actually good to get feedback so that you know all of those who have been given the } \\
\text { report and what the outcome was (FG2 P6). }\end{array}$ \\
\hline
\end{tabular}

\section{Violence is part of the job}

Many forms of violence were habitually accepted by the nurses because it became part of their normal working day. Although most participants indicated that they had not experienced physical violence, all stated that they had experienced verbal aggression on a regular, almost daily, basis. Despite the frequency of verbally violent incidents, most participants did not believe this constituted violence, and as a consequence, did not formally report it (Table 3). 
Accepting violence from 'sick' patients

Most participants indicated that they were more accepting of violent patients who were 'sick' as opposed to violent patients who were "behaving badly"' (FG1 P1). Participants rationalised that the violent behaviour of 'sick' perpetrators was not intentional, but if a patient or relative was intoxicated or just angry, then they were considered worthy of reporting (Table 3).

\section{Barriers to formal reporting of violence}

\section{RiskMan was difficult and time-consuming}

The most frequent reason given for not formally reporting WPV, and a significant barrier to reporting, was the reporting system itself. Participants overwhelmingly agreed that they found the RiskMan software difficult, "not user-friendly" (FG1 P7), "complicated" (FG2 P2), and "difficult to understand" (FG2 P6). They indicated that the reporting system was rigid with no options for flexibility. For example, they had to select "categories" (FG2 P4) rather than using "free text" (FG2 P4). In addition, RiskMan was reported to be extremely time-consuming, and while they recognised that it was important to report WPV, participants indicated that they lacked the time required to complete the formal report (Table 3). One participant indicated that they reported violence in the patient's file rather than RiskMan because if RiskMan were used "you' $d$ be tied up with the computer ... [patient care] would stand still".

\section{Lack of clear policies and procedures}

It was evident that participants were unclear about what the processes were, if a violent incident was reported. Some participants thought that the hospital had a zero tolerance policy, which meant that perpetrators of violence would be removed from the ED. Other participants believed the zero tolerance policy was not enforced. In fact, the hospital where this study was conducted did not have a zero tolerance policy in place (Table 3 ).

\section{Not encouraged to report}

Most participants indicated that they had not been encouraged to report violence. Some reported that they were never encouraged to report violence by anyone. Even after security had attended and a violent patient had been physically restrained, the nurses stated that they were not encouraged to formally report the incident (Table 3).

\section{No preventative measures post violent incident}

Participants expressed concern that once a violent incident was over, no action was taken to prevent a similar incident from occurring in the future. Consequently, participants did not see the value in time-consuming reporting, if there appeared to be no obvious benefit (Table 3).

\section{Enablers to reporting of violence}

\section{User-friendly system}

The participants said they would report violent incidents more often if there was a simpler, less time-consuming process to reporting. They indicated that a simpler type of formal reporting would expedite the process and enable greater participation in the practice of formal reporting. The willingness of participants to use a simpler reporting system was evidenced by their use of the existing patient alert system. When a patient's name was entered into the electronic record initially, an alert icon was generated in the record, which warned staff of any potential risk to themselves from that particular patient. This system was already being utilised by some of the participants, as it was quick and easy to use (Table 3 ).

\section{Feedback of formal reports}

When formal reports had been completed, participants indicated that they were able to track the progress of their report and able to learn the outcome. This was perceived to be beneficial (Table 3).

\section{Discussion}

The findings from this study concur with the findings of previous studies, and add to the evidence base that violence in the ED in one form or another is a regular, almost daily occurrence, and is underreported. Thus, it is of no surprise that previous studies have also highlighted that violence in EDs is prevalent and underreported by ED nurses. 2,8,15,16,21-25

The major barrier identified in this study to the reporting of WPV, was the existing formal reporting system, RiskMan. Participants overwhelmingly agreed that this system was difficult to use, time-consuming and they rarely used it. This finding is supported by the Drug \& Crime Prevention Committee ${ }^{8}$ report, which received several submissions from Victorian health organisations identifying similar problems with RiskMan and recommended evaluation of both the performance of the programme and the proportion of nurses using it. This study provides further evidence that RiskMan is not being well utilised by emergency nurses to report violence. Based on the findings of this current study, an evaluation of RiskMan is essential. The importance of using a formal reporting system for WPV (such as RiskMan) cannot be overemphasised. RiskMan notifies organisational management about each event, and collects data on prevalence and outcomes. The aggregate data collected from RiskMan is used to inform organisations, management, government and others about the number and nature of violent incidents. Reporting violent incidents via RiskMan is an Occupational Health and Safety (OHS) requirement in Victoria. ${ }^{26}$ Given that RiskMan is the existing formal reporting system, it is important that some modification be made to establish the true nature and number of the incidents of WPV in the ED. Whilst it is valuable to have a uniform state-wide reporting system, there is little benefit having a reporting system designed to capture the number of violent events, if the system itself is too complex to use and essentially not all nurses are prepared to use it all of the time.

The evidence was clear however, that although nurses in this study did not report WPV formally on RiskMan, they did report WPV and chose to use a number of other informal methods by which to report, such as documentation in the medical record and using the patient alert system. The benefit of using these reporting methods was that they were easier and less time-consuming to use. 
Participants indicated that a simplified system, that took less than ten minutes to complete, would encourage reporting of WPV. This is an important finding, and was supported by the participants' use of the existing patient alert system, which is simple and quick to complete. However, given that the participants generally accepted WPV as part of the job, and did not consider verbal abuse to be a violent act, it was unclear if a simplified reporting system would increase the frequency of reporting of WPV. There is a paucity of research investigating simpler forms of reporting and whether this improves reporting rates. ${ }^{7,8,27}$

The findings in this study clearly demonstrate that violence in the workplace is endemic, and as such normalises violence. Attitudes of the participants in this study towards violence and verbal aggression in particular, prevented them from reporting violence. This study revealed that nurses made excuses for patients' violent behaviour and also accepted violence as just part of the job. This finding is consistent with previous studies which report that nurses excuse a patient's violent behaviour. ${ }^{2,27,28}$ Verbal aggression has become so commonplace it is accepted as part of the nature of the workplace. This attitude normalises violence and therefore it is not seen as a problem. ${ }^{7,8,23}$ This mindset is entrenched as part of a workplace culture. Unless changes are made to alter workplace culture, verbal aggression perpetrated by both patients and their relatives, will continue to go unreported and nurses will continue to endure such mistreatment. $2,6,7$

In the ED where this study was conducted, there were posters placed on the walls near the triage area warning that violence in the ED was unacceptable. Yet the participants felt they had no control over exposure to violence. There was a general lack of focus on the issue, and even though the ED had some systems in place, participants felt they had no choice but to be exposed to violence. Some participants incorrectly thought there was a zero tolerance policy towards violence. This confusion, or lack of knowledge, highlighted the distance between the nurses, policy makers, and effective action. It is therefore important to involve the nurses working directly with patients and families in the process of designing better systems, because they are encountering these issues daily and can best inform what changes are required. This would ultimately empower nurses with knowledge about the importance of managing violence and reporting so that there are more positive outcomes for nurses and patients in the future.

\section{Limitations}

While the sample size $(n=15)$ may be considered too small for transferability of findings, the phenomenological approach taken in this study did provide important data from experienced emergency nurses in one large metropolitan ED, resulting in new insights into the underreporting of violence in the ED. In addition, the sample comprised of self-selecting voluntary participants, and as such may have had a degree of inherent bias, for example, a participant may hold a particularly strong view on the subject. Also participants in a public forum such as a focus group, may be reluctant to speak freely in the presence of their colleagues, and this may lead to an exaggeration of the findings. ${ }^{29}$

\section{Recommendations}

There are four key recommendations arising from this study:

- Emergency nurses need to be engaged in the development of WPV policies and procedures in order to have more control over their work environment. This could empower nurses with a sense of control leading to a more proactive approach to WPV and subsequently, the reporting of it.

- RiskMan needs to be evaluated and revised, to enable nurses to formally report WPV more quickly. One solution for this may be to integrate the current systems used to report violence (for example the patient alert system) with RiskMan, so that a single, quick entry, can generate the organisational and state wide data required. Reporting rates in the RiskMan system are unlikely to improve if the existing reporting system is maintained.

- Education of emergency nurses to raise awareness of verbal abuse as a form of violence, and to emphasise the importance and benefits of reporting.

- Conduct of a larger, multi-site, participatory action research study to address the factors related to violence in the ED.

\section{Conclusion}

This study has shown that nurses do report violence, albeit not formally, using easier methods to report. The complexity of the current formal reporting system, RiskMan, was identified as the most significant barrier to reporting violence in this ED. Nurses' attitudes to violence and a lack of a clear definition of violence influenced their decision to report. Furthermore, there was evidence that nurses were highly selective about which incident was worthy of a formal detailed report. In addition, participants were unaware of the hospital's policies and procedures regarding violence. In essence, their decision to report violence depended on nurses' personal attitudes concerning violence and the systems in place for reporting.

\section{Provenance and conflict of interest}

There are no conflicts of interest. This paper was not commissioned.

\section{Funding}

This study received no funding.

\section{Acknowledgements}

This study was undertaken in partial fulfilment on a Master of Nursing qualification. The authors gratefully acknowledge the emergency nurses who volunteered their time and expertise to participate in this study. 


\section{References}

1. Catlette M. A descriptive study of the perceptions of workplace violence and safety strategies of nurses working in level 1 trauma centers. J Emerg Nurs 2005;31(7): 519-25.

2. Chapman R, Styles I, Perry L, Combs S. Examining the characteristics of workplace violence in one non-tertiary hospital. $J$ Clin Nurs 2010;19:479-88.

3. Gates DM, Ross CS, McQueen L. Violence against emergency department workers. J Emerg Med 2006;31:331-7.

4. Lau JBC, Magarey J, McCutcheon H. Violence in the emergency department: a literature review. Aust Emerg Nurs J 2004;7(2):27-37.

5. Gates D, Gillespie G, Smith C, Rode J, Kowalenko T, Smith B. Using action research to plan a violence prevention program for emergency departments. J Emerg Nurs 2011;37(1):32-9.

6. Gates DM, Gillespie GL, Succop P. Violence against nurses and its impact on stress and productivity. Nurs Econ 2011;29(2): 59-67.

7. Griffiths D, Morphet J, Innes K. Occupational violence in healthcare. Melbourne: Institute for Safety, Compensation and Recovery Research; 2015.

8. Parliament of Victoria. Inquiry into violence and security arrangements in Victorian hospitals and, in particular, emergency departments. Melbourne: Drugs and Crime Prevention Committee; 2011.

9. Laschinger HK, Leiter MP. The impact of nursing work environments on patient safety outcomes: the mediating role of burnout/engagement. J Nurs Adm 2006;36(5): 259-66.

10. Kowalenko T, Gates D, Gillespie GL, Succop P, Mentzel TK. Prospective study of violence against ED workers. Am J Emerg Med 2013;31(1):197-205.

11. Perone S. Violence in the workplace. Canberra, Australia: Australian Institute of Criminology; 1999.

12. Australian Nursing Federation (Victorian Branch). Submission into inquiry into violence and security arrangements in Victorian hospitals. Melbourne: ANF; 2007.

13. WorkSafe Victoria. Prevention and management of aggression in health services. Melbourne; 2008.
14. Department of Human Services. Victorian taskforce on violence in nursing final report. Melbourne: State Government of Victoria; 2005.

15. Kennedy MP. Violence in emergency departments: under reported, unconstrained and unconscionable. Med J Aust 2005; 183(7):362-5.

16. Taylor JL, Rew L. A systematic review of the literature: workplace violence in the emergency department. J Clin Nurs 2010;20(12):1072-85.

17. Balls P. Phenomenology in nursing research: methodology, interviewing and transcribing. In: Nursing Timesnet.; 2009 [Internet]. Available from: http: / / www. nursingtimes.net/ nursing-practice-clinical-research

18. Laverty M. Hermeneutic phenomenology and phenomenology: a comparison of historical and methodological considerations. Int J Qual Methods 2003;2(3):1-25.

19. Polit DF, Beck CT, editors. Nursing research principals and methods. 7th ed. London: Lippincott Williams and Wilkins; 2010.

20. Crotty M, editor. Phenomenology and nursing research. South Melbourne: Churchill Livingston; 1996.

21. Ferns T. Violence in the accident and emergency departmentan international perspective. Accid Emerg Nurs 2005;13:180-5.

22. International Council of Nurses. Increasing violence in the workplace is a threat to nursing and the delivery of health care. Geneva; 1999.

23. Lyneham J. Violence in New South Wales emergency departments. Aust J Adv Nurs 2000;18(2):8-17.

24. Pich J, Hazelton M, Sudin D, Kable A. Patient related violence against emergency department nurses. Nurs Health Sci 2010;12(3):268-73.

25. Pich J, Hazelton M, Sudin D, Kable A. Patient-related violence at triage: a qualitative descriptive study. Int J Emerg Nurs 2011;19:12-9.

26. Occupational Health and Safety Act. Act No. 107/2004. Melbourne; 2004.

27. Pawlin S. Reporting violence. Emerg Nurse 2008;16(4):16-21.

28. Jones J, Lyneham J. Violence: part of the job for Australian nurses? Aust J Adv Nurs 2000;18(2):27-32.

29. Tench MR, Taylor B, Kermode S, Roberts K, editors. Research in nursing evidence for best practice. 4th ed. Melbourne: Cenage Learning; 2010. 